\title{
Proteomic similarity of the Littorinid snails in the evolutionary context
}

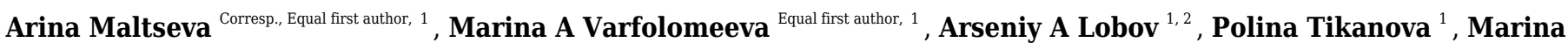 \\ Panova $^{1,3}$, Natalia A Mikhailova ${ }^{1,4}$, Andrei I Granovitch ${ }^{1}$ \\ 1 Department of Invertebrate Zoology, St. Petersburg State University, St. Petersburg, Russia \\ 2 Laboratory of Regenerative Biomedicine, Institute of Cytology Russian Academy of Sciences, St. Petersburg, Russia \\ 3 Department of Marine Sciences, University of Gothenburg, Tjärnö, Sweden \\ ${ }^{4}$ Centre of Cell Technologies, Institute of Cytology Russian Academy of Sciences, St. Petersburg, Russia \\ Corresponding Author: Arina Maltseva \\ Email address: arina.maltseva@spbu.ru
}

Background. The introduction of DNA-based molecular markers made a revolution in biological systematics. However, in cases of very recent divergence events, the neutral divergence may be too slow, and the analysis of adaptive part of the genome is more informative to reconstruct the recent evolutionary history of young species. The advantage of proteomics is its ability to reflect the biochemical machinery of life. It may help both to identify rapidly evolving genes and to interpret their functions.

Methods. Here we applied a comparative gel-based proteomic analysis to several species from the gastropod family Littorinidae. Proteomes were clustered to assess differences related to species, geographic location, sex and body part, using data on presence/absence of proteins in samples and data on protein occurrence frequency in samples of different species. Cluster support was assessed using multiscale bootstrap resampling and the stability of clustering - using cluster-wise index of cluster stability. Taxon-specific protein markers were derived using IndVal method. Proteomic trees were compared to consensus phylogenetic tree (based on neutral genetic markers) using estimates of the Robinson-Foulds distance, the Fowlkes-Mallows index, and cophenetic correlation.

Results. Overall, the DNA-based phylogenetic tree and the proteomic similarity tree had consistent topologies. Further, we observed some interesting deviations of the proteomic littorinid tree from the neutral expectations. (1) There were signs of molecular parallelism in two Littoraria species that phylogenetically are quite distant, but live in similar habitats. (2) Proteome divergence was unexpectedly high between very closely related Littorina fabalis and L. obtusata, possibly reflecting their ecologydriven divergence. (3) Conservative house-keeping proteins were usually identified as markers for cryptic species groups ("saxatilis" and "obtusata" groups in the Littorina genus) and for genera (Littoraria and Echinolittorina species pairs), while metabolic enzymes and stress-related proteins (both potentially adaptively important) were often identified as markers supporting species branches. (4) In all five Littorina species British populations were separated from the European mainland populations, possibly reflecting their recent phylogeographic history. Altogether our study shows that proteomic data, when interpreted in the context of DNA-based phylogeny, can bring additional information on the evolutionary history of species. 


\section{Proteomic similarity of the Littorinid snails in the}

\section{2 evolutionary context}

3

4 Arina L. Maltseva ${ }^{1}$, Marina A. Varfolomeeva ${ }^{1}$, Arseniy A. Lobov ${ }^{1,2}$, Polina O. Tikanova ${ }^{1}$,

5 Marina Panova ${ }^{1,3}$, Natalia A. Mikhailova ${ }^{1,4}$ and Andrei I. Granovitch ${ }^{1}$ 6

71 Department of Invertebrate Zoology, St Petersburg State University, St Petersburg, Russia

82 Laboratory of Regenerative Biomedicine, Institute of Cytology Russian Academy of

9 Sciences, St Petersburg, Russia

103 Department of Marine Sciences - Tjärnö, University of Gothenburg, Sweden

114 Centre of Cell Technologies, Institute of Cytology Russian Academy of Sciences, St

12 Petersburg, Russia

13

14 Corresponding author:

15 Arina Maltseva

16 Universitetskaya 7/9A, St Petersburg, 199034, Russia

17 arina.maltseva@spbu.ru; 


\section{Abstract}

21 Background. The introduction of DNA-based molecular markers made a revolution in

22 biological systematics. However, in cases of very recent divergence events, the neutral

23 divergence may be too slow, and the analysis of adaptive part of the genome is more informative

24 to reconstruct the recent evolutionary history of young species. The advantage of proteomics is

25 its ability to reflect the biochemical machinery of life. It may help both to identify rapidly

26 evolving genes and to interpret their functions.

27 Methods. Here we applied a comparative gel-based proteomic analysis to several species from

28 the gastropod family Littorinidae. Proteomes were clustered to assess differences related to

29 species, geographic location, sex and body part, using data on presence/absence of proteins in

30 samples and data on protein occurrence frequency in samples of different species. Cluster

31 support was assessed using multiscale bootstrap resampling and the stability of clustering - using

32 cluster-wise index of cluster stability. Taxon-specific protein markers were derived using IndVal

33 method. Proteomic trees were compared to consensus phylogenetic tree (based on neutral genetic

34 markers) using estimates of the Robinson-Foulds distance, the Fowlkes-Mallows index, and

35 cophenetic correlation.

36 Results. Overall, the DNA-based phylogenetic tree and the proteomic similarity tree had

37 consistent topologies. Further, we observed some interesting deviations of the proteomic

38 littorinid tree from the neutral expectations. (1) There were signs of molecular parallelism in two

39 Littoraria species that phylogenetically are quite distant, but live in similar habitats. (2)

40 Proteome divergence was unexpectedly high between very closely related Littorina fabalis and

41 L. obtusata, possibly reflecting their ecology-driven divergence. (3) Conservative house-keeping

42 proteins were usually identified as markers for cryptic species groups ("saxatilis" and "obtusata"

43 groups in the Littorina genus) and for genera (Littoraria and Echinolittorina species pairs), while

44 metabolic enzymes and stress-related proteins (both potentially adaptively important) were often

45 identified as markers supporting species branches. (4) In all five Littorina species British 
46 populations were separated from the European mainland populations, possibly reflecting their

47 recent phylogeographic history. Altogether our study shows that proteomic data, when

48 interpreted in the context of DNA-based phylogeny, can bring additional information on the

49 evolutionary history of species.

\section{Introduction}

Phylogenetic analysis strives to reconstruct the evolutionary history based on variation in heritable traits. At least in some cases, the divergence is considered to be driven by adaptation [1-2]. Similar phenotypes (at the molecular levels also) might be formed independently under similar conditions, which is classified as either parallelism or convergence, depending on the degree of genetic relatedness $[3,4]$. With respect to this, phenotypic traits alone obviously might be deceptive in phylogenetic studies.

The methodological breakthrough in DNA analysis introduced the molecular markers into phylogenetic studies and led to the development of several quantitative approaches to reconstruct evolutionary processes from DNA variation [5-8]. Throughout the "era of DNA-markers" adaptive neutrality has been the central prerequisite [9-11]. Phylogenetic distance (in terms of divergence time) ought to be measured by random neutral (not adaptive, or affected by genetic hitchhiking, or epistasis, etc.) genetic differentiation. Phylogeny was expected to reflect wholegenome, not locus-specific history since the latter might undergo very strong and fast changes $[10,12-13]$

Following the rapid development of sequencing techniques, the next step was taken towards phylogenomics and multi-locus phylogenies $[9,13-15]$. The growing number of loci in analyses often provides more confident phylogenetic inferences, but also inevitably includes some loci that are under different types of selection, linked to selected loci or even originated by introgression from other species $[9,16-17]$. It is now evident that evolutionary changes affect 
70 genome unevenly: there are outlier loci, sometimes forming "islands of speciation", important

71 for fitness and adaptation and consequently displaying outlying pattern of variation [18-22].

72 From traditional neutral phylogenies we are moving to the whole-genome view of divergence,

73 incorporating contributions of adaptation, introgression and hybridization.

74 Yet, even though the DNA-markers approach is able to answer many important

75 evolutionary questions, it is not able to answer all of them. The idea of distinctiveness of

76 species trees from gene trees has a long history since early 1960s [23] until now [24]. For

77 example, Degnan \& Rosenberg showed that, if five or more species are regarded, there always

78 exist branch lengths for a species tree topology, for which gene tree mismatch is more common

79 than concordance between gene and species trees [25]. Even though some efforts were put to

80 minimize misleading effects [e.g. 26], "the diversity recovered in our surveys of DNA sequence

81 evolution within and between species is ultimately an indirect and incomplete window into the

82 history of species" (e.g. due the different level of complexity of such entities as genes or

83 genomes $v s$ organisms, population and species) [27]. Other reasoning can also be added. Firstly,

84 genomic tools are "too far" from phenotype with its functional aspects, which calls for

85 additional, more physiologically / biochemically relevant approaches to fill this gap and make

86 feasible functional interpretation of observed genetic differences [rev e.g. in 28-29]. Secondly,

87 while phylogeny is a reconstruction of the evolutionary history from the variation in the

88 inherited traits, it is now generally accepted that heritable information in living systems is

89 represented not only by genetic information [30-32]. The incorporation of some non-genetic

90 inheritance phenomena (such as niche construction, developmental bias, epigenetic regulation,

91 etc.) into evolutionary thinking gave birth to the so called "extended synthesis" [33-35].

92 Although the need for a revision of the evolutionary theory is being debated [see e.g. 36], the 
93 role of non-genetic inheritance in phenotype evolution can no longer be neglected. One way to

94 incorporate non-genetic inheritance is, again, to include phenotypic data in evolutionary

95 analyses. Thirdly, when analyzing events at shallow evolutionary time scale, the resolution of

96 traditional neutral markers might be insufficient [rev. in 9]. In the case of ecological speciation

97 (i.e. adaptation-driven sympatric divergence), the neutral whole-genome divergence might be

98 too slow to tell something about a short evolutionary history of a young species. Here again, the

99 neutral genetic / genomic data need to be supplemented by information on fast evolving parts of

100 a living entity (even though the opposite examples are known as well [see 37-38]). There are

101 multiple examples of using fast-evolving outlier loci to reconstruct recent ecological speciation

$102[1,18-21,39]$. However, outliers in a broad sense are not just non-neutrally evolving loci

103 revealed by genome-scans; they underlie proteomic, metabolomics (or morphological,

104 ecological, behavioral, etc.) traits. Analysis of variability in the traits instead of focusing solely

105 on underlying DNA sequences gives us a chance for causative functional explanation of the

106 observed differences, and can bring essentially new information on the evolutionary history of a

107 species.

108 "The fabric of life is protein-based" [40], and the proteome as a molecular phenotype trait

109 is a potentially useful tool for evolutionary studies for several reasons. (1) Protein qualitative /

110 quantitative expression patterns obviously cannot be deduced from genomic data; as the

111 proteome mediates interaction of a genome with the environment, it brings non-redundant

112 information about the physiology of organisms. (2) Protein expression pattern cannot be inferred

113 from transcriptomic data either, as mismatches in quantities of proteins and their corresponding

114 transcripts have been repeatedly detected [41-45]. (3) Non-genetic inheritance potentially

115 important for speciation and maintenance of species integrity will affect the expression of 
116 proteins [32]. The earliest taxonomic applications of proteomics date back to the beginning of

11780 s [46-47] before they were replaced by DNA sequence analysis. Since then, proteomics studies

118 have been used in a wide range of evolutionary areas, such as ecology, population biology,

119 taxonomy, and evolutionary physiology [40,48-54] but still proteomics is far behind genomics

120 in its popularity.

121 We applied this rationale to an example of the gastropods family Littorinidae

122 (periwinkles), using the proteome as a molecular phenotype trait. These marine intertidal

123 mollusks have been model objects for various studies in evolutionary biology, ecology and

124 adaptation [55-73]. Littorinids provide an opportunity to analyze both closely and more distantly

125 related species from several genera inhabiting contrasting biotopes: Echinolittorina and

126 Littoraria in tropic and subtropic regions; Littorina in moderate and subarctic regions. The set of

127 Northern Atlantics species belongs to the latter genus, forming two subgenera Littorina subgen.

128 Littorina Férussac, 1822 and Littorina subgen. Neritrema Récluz, 1869 [74]. The subgenus

129 Neritrema includes two groups of closely related species - the "obtusata"- group (L. obtusata

130 (Linnaeus, 1758) and L. fabalis (W. Turton, 1825)) and "saxatilis"- group (L. saxatilis (Olivi,

131 1792), L. arcana Hannaford Ellis, 1978 and L. compressa Jeffreys, 1865). The sister subgenus to

132 Littorina Neritrema is Littorina Littorina, containing, among others, L. littorea (Linnaeus, 1758).

133 The relationships among the littorinid genera, the subgenera and "obtusata" and "saxatilis" clades

134 are well resolved based both on morphology and several neutral DNA loci [74-76]. The

135 hierarchy within the "saxatilis" species group still remains rather questionable, and these three

136 species grouped in different combinations depending on the molecular approach used [e.g.

$13765,70,74,76-80]$. Altogether the littorinids with their well-established molecular phylogeny, some 
138 distantly related species living in similar biotopes and other closely related species inhabiting

139 contrasting biotopes, represent a good model for comparative proteomic studies.

140 The present study aims to assess the utility of proteome variation to infer the evolutionary

141 history of the species under investigation. We do not attempt to infer the true species tree by this

142 quantitative-proteomic approach. Instead, we compare adaptively neutral (represented by neutral

143 DNA-loci) and adaptively non-neutral (evaluated by proteomics) parts of the molecular

144 machinery. Firstly, we compare overall patterns of proteome variation in the littorinids to a well-

145 established phylogeny based on neutral DNA markers. Secondly, we focus on discrepancies

146 between the DNA and proteome trees and attempt to interpret them in the light of the existing

147 knowledge on evolution and ecology of the species and on the function of the involved proteins.

148 Materials and Methods

$149 \quad$ 1. Ethics statement. Periwinkles were collected from wild populations (Table 1).

150 Periwinkles are not endangered or protected species in the study regions, so no special

151 permission for their collection was required. Administrations of the Swire Institute of Marine

152 Science, Hong Kong University (Hong Kong, China), the Arctic University of Norway

153 University of Tromsø (Norway), the Educational and research station "Belomorskaia" of St.

154 Petersburg State University (Russia), the Scotland Association of Marine Science (Oban,

155 Scotland, UK) and Interuniversity Institute for Marine Sciences (Eilat, Israel) were informed

156 about the snails sampling. Collection and animal numbers were approved by these authorities.

157 No special approval could be obtained for sample collection at the site near Cancale (France)

158 because it is not an area of any national park or a private territory, so there was no appropriate

159 authority to apply for permission.

160 2. Sample collection and preparation. Adult individuals of littorinid snails Littorina

161 littorea (Linnaeus, 1758), Littorina fabalis (W. Turton, 1825), Littorina obtusata (Linnaeus, 
162 1758), Littorina arcana Hannaford Ellis, 1978, Littorina compressa Jeffreys, 1865, Littorina

163 saxatilis (Olivi, 1792), Littoraria ardouiniana (Heude, 1885), Littoraria 'melanostoma E Asia'

164 (is unnamed, see [81]), Echinolittorina millegrana (Philippi, 1848) and Echinolittorina

165 marisrubri Reid, 2007 were collected from wild populations in six geographic locations (Table $1661)$.

167 After collection animals were transported to the laboratory. The Littorina snails from the

168 Northern Atlantic were kept in aerated moist containers at $8{ }^{\circ} \mathrm{C}$ and rinsed with salt water once a

169 day. Snails were acclimated to these standard conditions for no less than two days and no longer

170 than one week before dissection. The Echinolittorina and Littoraria snails from the Red and

171 East-China Sea coasts, respectively, were kept in dry containers at room temperature and rinsed 172 with salt water once a day.

173 For sample preparation snails were dissected under MBS-10 binocular microscope at 79-

174849 magnifications to identify species, sex and possible trematode or other heavy parasitic 175 infection and to separate body parts (head, foot and penis). The mollusks identification was 176 conducted according to the shell form, sculpture and pigmentation, as well as male and female

177 reproductive system anatomy [74,82-84]. The correctness of the tropical species identification

178 was confirmed by Dr. David G. Reid personally. The identification of the species within the

179 Littorina "saxatilis"- and "obtusata"- groups (the most challenging part) was performed as

180 described previously [74,82]. More details can be found in the S1 File. Only the reliably

181 identified mature individuals with well-developed reproductive system and free of trematode or 182 other obvious infection were used in further analysis.

183 Tissues of up to 20 animals (collected from different parts of intertidal area within the

184 same location) were pooled separately for different body parts (foot, head, penis) and sexes; and 
185 homogenized in lysis buffer (7M urea, 2M thiourea, 4\% CHAPS, $25 \mathrm{mM}$ Tris, $\mathrm{pH}$ 8.2) using

186 Mixer Mill MM 400 (Retsch). Particles were sedimented by centrifugation 12000 g, 15 min, 4

$187{ }^{\circ} \mathrm{C}$ and supernatants were frozen at $-80{ }^{\circ} \mathrm{C}$ until use.

188 3. Proteomic analysis strategy. The "biological noise of the system" due to individual

189 variations and microniche adaptation was leveled by pooling, the short acclimation procedure

190 and including biological replicates into the analysis [rev. in 85]. Samples of somatic tissues of

191 males and females were used as biological replicates, as a previous study showed no significant

192 sex effect at the qualitative level [70]. Head and foot tissues used for analysis in this study are

193 less sensitive to transient environmental impacts than e.g. gill as was demonstrated earlier in a

194 study about salinity stress [71]. Technical replicates (at least two for every sample) were

195 averaged to reduce "technical noise" [85]. Altogether this strategy ensures the analysis of the

196 most stable and reproducible proteome, reducing accidental impacts.

197 In general, the qualitative strategy of a proteomic study aims for the characterization of the

198 set of proteins present in a sample. This was successfully applied to characterize proteomes of

199 different compartments (organelles, tissues, organs) and certain classes of proteins etc., being an

200 integrative part of structural biology. The quantitative approach estimating proteins abundances

201 is a part of functional biology, and is more informative for studies of physiological changes,

202 adaptive mechanisms, etc. [rev. in 86]. We chose the qualitative approach to compare basic

203 proteomes between species since it is less amenable to transient physiological and environmental

204 impacts. Our approach principally resembles the blind whole-genome assaying methods like

205 AFLP, RFLP, RAPD, etc. in the sense of that the identity of analyzed proteomic markers

206 (protein spots) is unknown. The main difference is taking into account the "working part of the

207 living molecular machinery", i.e. the proteome, while abovementioned methods engage DNA- 
208 regions, both coding and noncoding. We separated proteins in two-dimensional gel

209 electrophoresis, and ultimately, estimated the number of common and unique (new or altered due

210 to amino acid substitutions, modifications, splicing patterns, etc.) protein signals in single species

211 or species groups in comparison (more details on our approach and rationale of proteomic $v s$

212 genetic data comparison can be found in the S1 File).

213 We followed a gel-based methodology because it has, among others, an advantage of

214 whole-protein analysis and consequently saves combinations of different post-translational

215 modifications as individual signals [87]. We used differential 2D-electrophoresis (DIGE [88])

216 because it allows the simultaneous analysis of up to three samples within the same gel (allowing

217 the reliable detection of even minor structural changes) and provides high sensitivity of protein

218 detection (down to $150-500 \mathrm{pg}$ of a single protein) [89]. Qualitative gel analysis and spot

219 matching were carried out using PDQuest Advanced 8.0.1 software (BioRad, USA) by making

220 whole experiment master gel, allowing for the warping of individual gel scans [90]. Spots were

221 considered reliably detected if they were detected in at least two technical replicates of the same

222 sample, or in one technical replicate in at least two different samples. We have taken into

223 account potential post-translational modifications and/or splice variants by identifying

224 independent signals, because every particular modification/splice form possesses its own features

225 and functions, and appearance of a new form/modification represents an important evolutionary

226 event, comparable to amino acid(s) substitution or even the emergence of a new protein. In total,

227796 spots were used for inter-species comparison of proteomes. Protein spots differing between

228 species and available for excision after Coomassie gel staining were subjected to tandem mass

229 spectrometry MS/MS-analysis for identification following standard "bottom up" protocol.

230 Basically, in this method proteins are digested into peptides prior to MS/MS-analysis, molecular 
231 masses of resulting peptides and their fragments (after fragmentation in the collision cell of

232 mass-spectrometer during MS/MS-analysis) are determined and compared with MS-spectra

233 predicted from a database by software (see Supplement S1 File for more details). The success or

234 failure in protein identification did not influence the results of inter-specific comparisons, and

235 aided only in their interpretation (more details on experimental procedures can be found in

236 S1_File).

237 4. Statistical analysis. All analyses were run using R [91].

238 Clustering. Proteomic data were analyzed at two levels. First, data on presence/absence of

239 proteins in samples were used to assess proteomic differences related to geographic location, sex

240 and body part. Second, "consensus" species proteomes were constructed to assess the overall

241 similarity of species proteomes. A protein present in at least one sample of a given species was

242 considered as present in that species. These two datasets were analyzed in the same way: Jaccard

243 dissimilarity index was computed, dendrograms were derived using neighbour joining (NJ) and

244 unweighted pair group method with arithmetic mean (UPGMA) and plotted with dendextend

245 package [92]. Suitability of NJ vs UPGMA clustering methods was checked using plots of

246 pairwise distances on a tree vs. original pairwise distances. The both methods yielded

247 comparable results for sample clustering (S2 File); NJ performed slightly better for clustering of

248 consensus species proteomes (S2 File).

249 Stability of clustering. Branch support was assessed by approximately unbiased (AU) p-

250 values using multiscale bootstrap resampling [93] with 10000 iterations in the pvclust

251 package [94]. This number of iterations ensured accurate estimation of AU $p$-values (their

252 standard errors were less than 0.01). Branch support for midpoint-rooted NJ-based trees was

253 assessed using bootstrap with 1000 iterations [95] in the ape package [96]. Stability of 
254 UPGMA-based sample clustering was additionally assessed using nonparametric bootstrap with

25510000 iterations in the fpc package [97-99]. After the original tree was split into a specified

256 number of clusters, an index of cluster stability was computed cluster-wise as a mean Jaccard

257 similarity $(\mathrm{J})$ of the actual cluster to the most similar cluster in a bootstrapped data. $\mathrm{J}>0.75$

258 corresponds to stable and successfully recovered clusters, while $\mathrm{J}<0.5$ marks "dissolved"

259 clusters with uncertain grouping of objects. In addition, the bootstrap samples allowed to

260 estimate the probability of recovering a particular cluster when the underlying data change.

261 Cluster markers. The qualitative differences of the periwinkle proteomes were assessed

262 using indicator species analysis (IndVal) with the indicspecies package [100]. The IndVal

263 method measures the strength of association of specific features with particular groups of

264 samples. It was originally developed in community ecology and has been successfully used for

265 detection of molecular markers [101]. We have run several analyses to detect taxon-specific

266 protein markers using the data on presence/absence of proteins in the samples (for each of the 10

267 species individually, Littoraria (L. ardouiniana + L. melanostoma), Echinolittorina (E.

268 millegrana + E. marisrubri), the pair L. arcana $+L$. saxatilis, the "saxatilis"-species group $(L$.

$269 \operatorname{arcana}+$ L. saxatilis + L. compressa) of the Littorina (subgen. Neritrema), the "obtusata"-

270 species group (L. fabalis + L. obtusata) of the Littorina (subgen. Neritrema), the subgenus

271 Neritrema (genus Littorina), and genus Littorina (subgenera Neritrema + Littorina)). Group-

272 equalized version of IndVal was used to avoid biases due to unbalanced group sizes [100]. The

$273 p$-values of the IndVal statistic were corrected for false discovery rate in multiple tests (FDR)

274 using Benjamini-Hochberg correction [102]. The proteins with a significant indicator value

275 (FDR-adjusted $p \leq 0.05$ ) were used to compute specificity (the probability that the sample

276 belongs to the target category given the particular protein has been found), and sensitivity (the 
277 probability of finding the protein given the sample belongs to the target category) of cluster 278 markers.

279 5. Phylogenetic analysis. We used sequence data from the previous extensive study on

280 littorinid phylogeny [76] to produce a tree only for those species that are included in the present

281 study. Fragments of 28S rRNA, 12S rRNA and cytochrome oxidase subunit I (COI) were

282 obtained from NCBI; information about sequences used is available in S1 File. Sequences were

283 concatenated with different genes allowed to evolve independently. Phylogenetic analysis was

284 performed using Bayesian inference, MrBayes 3.2.6 [103] with the same parameters as in the

285 original study [76]: fragments of the three genes were used as a concatenated sequence, where

286 individual genes were unlinked to evolve independently; nucleotide substitution model was

$287 \mathrm{GTR}+\mathrm{G}+\mathrm{I}$; analysis was performed as two independent runs, five chains in each (four heated and

288 one cold; the first $25 \%$ samples from the cold chain were discarded) for 25000000 generations

289 with a sample frequency of 1000 , print frequency of 1000 and diagnostics calculated every 1

290000 generations. The convergence between two runs was tested by comparison of statistical

291 parameters in the Tracer Software (http://tree.bio.ed.ac.uk/software/tracer/).

292 Comparison of phylogenetic and proteomic trees. Prior to comparison, phylogenetic and

293 NJ-based proteomic trees were made ultrametric using non-negative least squares with the

294 phangorn package [104]. The Robinson-Foulds distance (both raw and normalized) between

295 unrooted trees was computed to assess the total number of partitions which are implied by one of

296 the trees, but not the other [105]. Compositional similarity of proteomic and phylogenetic trees

297 was evaluated using the Fowlkes-Mallows index [106]. Correspondence between inter-species

298 distances on the trees was measured using cophenetic correlation [107]. In addition, cophenetic

299 distances on the proteomic and phylogenetic trees were expressed as fractions of maximal tree 
300 distance to allow direct comparisons (the matrices of transformed distances are presented in Fig.

301 1).

302 Figure 1. Interspecies relations within the family Littorinidae. (A) Dendrogram of consensus species proteomes

303 obtained via neighbour joining based on Jaccard dissimilarities of protein occurrence frequency in samples of

304 different species. The bootstrap support values are shown. (B) The molecular phylogeny tree obtained via Bayesian

305 inference using concatenated partial gene sequences from 28S rRNA, 12S rRNA and cytochrome oxidase C subunit

306 I (COI). Support values are posterior probabilities. Prior to comparison, the both trees A and B were made

307 ultrametric using non-negative least squares. Robinson-Foulds distance between unrooted trees was RF $=2$

308 (normalized $\mathrm{RF}=0.143$ ). The cophenetic correlation between trees $\mathrm{A}$ and $\mathrm{B}$ is $\mathrm{CC}=0.801$; between raw $\mathrm{NJ}$ and

309 Bayesian trees it is 0.798 (C) Fowlkes-Mallows index comparing dendrograms A and B. Black line with dots shows

310 the change of the compositional similarity of clusters $(\mathrm{Bk})$ with the number of clusters $(\mathrm{k})$. Dashed line indicates $\mathrm{Bk}$

311 values under a null hypothesis of insignificant similarity of cluster' composition in the trees under comparison). Red

312 line depicts threshold values for rejection of the null hypothesis. (D) Matrices of cophenetic distances for the

313 proteomic and DNA-based trees expressed as a percentage of the total tree length. L. lit Littorina (Littorina) littorea,

314 L. obt Littorina (Neritrema) obtusata, L. fab Littorina (Neritrema) fabalis, L. sax Littorina (Neritrem) saxatilis, L.

315 arc Littorina (Neritrema) arcana, L. com Littorina (Neritrema) compressa, L. ard Littoraria ardouiniana, L. mel

316 Littoraria melanostoma, E. mil Echinolittorina millegrana, E. mar Echinolittorina marisrubri

317

318 Results

$319 \quad$ 1. General trees' topologies. We applied two algorithms for proteomes clustering

320 (Neighbor joining and UPGMA) which both gave similar results (Fig. 1,2, S2 File). We deduced

321 the overall similarity of species proteomes from their clustering based on presence/absence of

322 peptides in consensus proteomes (Fig. 1A, S2 File). These results were compared with a

323 phylogenetic tree obtained by Bayesian inference based on three molecular markers used earlier

324 by Reid et al. [76] (Fig. 1B, S2 File). The general trees' topologies were similar: the first split

325 was between genera - Littoraria, Echinolittorina and Littorina (however, the genera were split in

326 different order at the proteomic and genetic-based trees); then within Littorina subgenera ( $L$.

327 (Littorina) littorea and L. Neritrema spp. separated), and finally the "saxatilis"-group split from

328 the "obtusata"-group. This was confirmed by the low Robinson-Foulds distance (raw RF = 2,

329 normalized $\mathrm{RF}=0.43)$, high cophenetic correlation coefficient $(0.80)$, and by the distribution of 
330 the Fowlkes-Mallows index, which indicated significant compositional similarity for all numbers

331 of clusters, except nine (Fig. 1C). The discrepancy between the trees with nine clusters came

332 from the "saxatilis"- group species cluster, where three species grouped differently (Fig. 1): $L$.

333 compressa was a sister-group to the pair L. saxatilis / L. arcana in the proteomic tree and $L$.

334 saxatilis was a sister taxon to the pair L. compressa / L. arcana in the genetic one. Noteworthy,

335 clustering in the proteomic tree was supported by high bootstrap values, unlike low support 336 (0.66) of the "saxatilis"- cluster in the DNA-tree.

337 2. Interspecies cophenetic distances. On the whole, proteomic distances in general

338 exceeded genetic distances (the full matrices of distances, both genetic and proteomic, are

339 available in Fig. 1D). The most robust differences were as follows.

340 (A) Relationships in the "saxatilis" group species cluster. L. arcana and L. compressa were 341 considered phylogenetically close, but rather distant at the proteomic level (the proteomic and

342 genetic distances between $L$. arcana and L. compressa were 0.133 and 0.017 , respectively); on

343 the contrary, $L$. arcana was proteomically very similar to $L$. saxatilis in contrast to the genetic

344 distance (the proteomic and genetic distances between L. arcana and L. saxatilis were 0.021 and

3450.034 , respectively); the differences were even more profound if UPGMA clusterization

346 algorithm was applied (see S2 File).

347 (B) Distances in the "obtusata" group species cluster. L. fabalis and L. obtusata were identified 348 as phylogenetically very close but strongly diverged at the proteomic level (the proteomic and

349 genetic distances between $L$. fabalis and L. obtusata were 0.285 and 0.013 , respectively). Their

350 proteomic cophenetic distance is comparable with one between genetically distant Littoraria

351 ardouiniana and L. melanostoma (Fig. 1A, Littoraria species formed common cluster just one

352 step earlier than L. obtusata / L. fabalis, Table 2, S2 Table). 
353 (C) The Littoraria genus case. Similarly, proteomic distances were larger than genetic ones for

354 two Echinolittorina species and two Littorina subgenera (Littorina and Neritrema). At the same

355 time, two Littoraria species showed an unusual outcome: being phylogenetically quite distant,

356 they appeared a bit closer to each other at the proteomic tree (the proteomic and genetic distances

357 between $L$. ardouiniana and L. melanostoma were 0.313 and 0.324 , respectively), which might

358 be interpreted as a sign of physiological and molecular parallelism.

3. Effect of geography, sex and body part. To assess the effect of geography, sex and

360 body part on the similarity of proteome composition, we calculated the extended proteomic tree

361 of samples (Fig. 2, S2 File). The general topology of this tree was similar to the consensus one.

362 Almost all species formed clear species-clusters, which supports the potential taxonomic use of

363 proteomics. Nevertheless, there was an exception: the pair L. saxatilis / L. arcana formed a

364 mixed cluster, where the factor "body part" (and sometimes "geographic location") affected

365 proteome stronger than "species". This cannot be due to male species-misidentification, as

366 somatic samples of those males grouped together with unmistakably identified females of these

367 two species. The first within-cluster division splits the UK samples of both species from the

368 mainland ones, suggesting that the geographic variation surpassed the interspecific variability,

369 and a parallel pattern observed in the proteomes of these two species. Remarkably, distinct UK-

370 clades were also present within the species-clusters of L. obtusata, L. fabalis and L. compressa.

371 Figure 2. Dendrogram of proteome UPGMA clustering from samples of the 10 Littorinidae species (neighbor

372 joining-based clustering is presented in S2 File). Clustering was produced using the unweighted pair group method

373 with the arithmetic mean (UPGMA) algorithm based on Jaccard dissimilarity coefficients for the data on

374 presence/absence of proteins in the samples. Sample labels indicate species (L.arc: Littorina (Neritrema) arcana;

375 L.comp: Littorina (Neritrema) compressa; L.sax: Littorina (Neritrema) saxatilis; L.obt: Littorina (Neritrema)

376 obtusata; L.fab: Littorina (Neritrema) fabalis; L.lit: Littorina (Littorina) littorea; L.ard: Littoraria ardouiniana;

377 L.mel: L. melanostoma; E.mar: Echinolittorina marisrubri; E.mil: E. millegrana), location (Ru: White Sea, Russia;

378 Fr: English Channel, France; UK: Atlantic coast, Scotland; No: Barents Sea, Norway; Cn: East-China Sea, Hong

Peer) reviewing PDF | (2019:08:40334:2:0:NEW 5 Jan 2020) 
379 Kong; Il: Israel), sex (f: female; m: male) and body part (so: foot + head parts; pe: penis). The approximately

380 unbiased bootstrap support values are shown.

381

382

383

384

385

386

387

388

389

390

391

392

393

394

395

396

397

398

399

400

401

402

4. Cluster stability of samples and cluster markers. To further assess the proteome

species-specificity we analyzed the stability of sample clustering [97]. Splitting the bootstrapped tree of samples into 10 clusters (the number of species analyzed) resulted mainly in same-species clusters with high recovery probability (Table 2, S2 Table), with the exception of the L. arcana / L. saxatilis pair which formed two multi-species clusters, corresponding to European mainland and UK locations (both with maximal recover probability). All species branches were supported by the presence of highly reliable (i.e., maximum specificity and sensitivity) protein markers, except for L. saxatilis (Table 2), which appeared poorly distinguishable from L. arcana at the proteomic level. For L. arcana there were only two specific markers. Moreover, these two markers represent two forms of the same enzyme: the peptidyl-prolyl cis-trans isomerase, which additionally reflects the physiological similarity of these two species.

5. Markers analysis. We succeeded in the MS/MS-identification of several species (cluster) markers (of 796 protein spots analyzed 128 were successfully annotated, S1 and S3 Tables). Expectedly, the most efficient identification was based on a L. saxatilis database (LSD) search [66] and gave positive results mostly in the case of L. saxatilis and L. arcana $(\sim 50 \%$ efficacy) in comparison to other species ( 4-20\% efficacy, S3 Table). A variety of housekeeping proteins were usually revealed as markers of cryptic groups ("saxatilis" and "obtusata") and genera (Littoraria and Echinolittorina species pairs), such as protein disulfide isomerase, calreticulin, tropomyosin, troponin T, radular globin, etc. Metabolic enzymes and stress related proteins (both potentially adaptively important), like arginine kinase, fructose-bisphosphate aldolase, malate dehydrogenase, peptidyl-prolyl cis-trans isomerase (PPIase), glutathione-S- 
403 transferase, etc., were often identified as species-branch supporting markers (the latter was also

404 the case for L. saxatilis / L. arcana pair vs L. compressa). The unusual pattern was found for the

405 Littoraria species pair, where species with quite long independent evolutionary history matched

406 by core metabolic enzymes (unlike, e.g. "saxatilis" group), but differed by globins (which were

407 common within either the "saxatilis" or "obtusata" group and within the Echinolittorina species 408 pair).

409 Discussion

410 In our analysis, the topology of the tree based on the Jaccard dissimilarities of consensus

411 proteomes (Fig. 1) proved to largely agree with the classic morphological [74] and the consensus

412 molecular phylogenies [76]. Moreover, in the tree inferred for location, sex and body part

413 specific samples the strongest differences of proteomes were observed between species: most

414 samples clustered by species (Fig. 2, except for L. arcana and L. saxatilis, discussed below).

415 This supports the taxonomic utility of proteomic studies, which also was demonstrated in other

416 organisms ranging from bacteria and protists to metazoans [48-49,52].

417 There are however some disagreements in branch length and topology of specific clades

418 between the DNA and proteome trees. Being a kind of molecular phenotype, the proteome

419 embodies both slowly evolving neutral and fast evolving adaptive evolutionary changes. In

420 contrast, classical phylogenetic analyses target neutral DNA loci. Thus, the comparison of these

421 two types of analyses (proteomic vs genetic molecular markers) can potentially bring some new

422 information about species evolutionary history, as discussed below.

\section{Similar proteomes in deeply diverged species: a possible case of the whole-}

424 proteome convergence / parallelism. In general, the proteomic distances in the trees exceeded

425 the genetic ones. This was rather expectable based on the inclusion of fast evolving proteins; e.g.

426 arginine kinases (present as several forms in periwinkles proteomes [70]) were among annotated 
427 proteins, and these enzymes are well known for their non-conservative nature [108]. However,

428 there was one remarkable exception from the "large proteomic distances"-rule. Two deeply

429 diverged Littoraria species appeared in the proteomic tree closer to each other than in the genetic

430 one. This result may be interpreted as a molecular parallelism. Although there are many known

431 examples of molecular convergence / parallelism (reviewed in Storz [109]), usually this

432 phenomenon is analyzed at the level of individual proteins of particular families, not the whole

433 proteome. There are strong theoretical arguments for molecular homoplasy resulting from neutral

434 and not adaptation-driven phenomena [110], e.g. a set of structural constraints, limiting protein

435 changes to certain trajectories (reviewed in $[109,111]$ ). Interestingly, in the present study another

436 tropical species pair E. marisrubri / E. millegrana (their estimated divergence-time is slightly

437 shorter than that of the Littoraria species, $\sim 35 \mathrm{Ma}$ and $\sim 48 \mathrm{Ma}$, respectively) [76] showed no

438 sign of proteomic parallelism, though both species pairs live under extreme conditions of thermal

439 stress, hypoxia and desiccation.. Nevertheless, adaptation to a rather special biotope in

440 mangroves, sympatrically inhabited by L. ardouiniana / L. melanostoma, could be another

441 possible explanation, as both species are ecologically very similar in terms of host-tree species

442 distribution, diet and activity [112-113]. Altogether, the example of the two Littoraria species

443 shows that similar proteomes can emerge from divergent genomes.

444 Interestingly, globin proteins deviate from the observed pattern of whole-proteomic

445 similarity, showing differences between the two Littoraria species. This may appear quite

446 puzzling; for comparison, no globin-related difference was observed between the strongly

447 diverged Echinolittorina species. A possible explanation for the globin divergence in Littoraria

448 species may be differences in their vertical distribution and expected different aerial-aquatic

449 respiration $\mathrm{VO}_{2}$-ratio [114-115]. Similarly, the "obtusata"- and "saxatilis"- groups differ in their 
450 preferences to littoral zone level $[82,116]$. Accordingly, they demonstrate different $\mathrm{VO}_{2}$-ratio

451 [114] and different globins, though these species are much more phylogenetically close

452 compared to the Echinolittorina species pair.

\section{$\underline{\text { 2. Distant proteomes in phylogenetically close species with different habitat }}$}

454 preferences. The species pair of the "obtusata" group - Littorina obtusata and L. fabalis shows a

455 pattern that is opposite to the one described above for Littoraria. In the Littorina "obtusata"

456 group we observed strongly diverged proteomes, apparently originating from very akin genomes

457 in morphologically similar species. These two species are phylogenetically very close (closer

458 than any other in the Littorinidae family; estimated divergence time is less $1 \mathrm{Ma}$ ) [76] and were

459 shown to share some mitochondrial haplotypes [117] (nevertheless, there are no signs of gene

460 flow between these two species [118]). Here, the comparative proteomic analysis revealed robust

461 differences between L. obtusata and L. fabalis. The distance between them highly exceeds those

462 within "saxatilis"- group. The discrepancy between genetic and proteomic similarities can be an

463 indirect evidence of ecological speciation. L. obtusata and L. fabalis demonstrate different

464 preferences in their microhabitat distribution: L. fabalis occupies lower intertidal and subtidal

465 levels, while L. obtusata prefers the middle littoral zone; at those levels, they are associated with

466 different fucoids $[74,82,116]$. One can hypothesize that partitioning of ecological niches drove

467 divergence at the physiological level, finally reflected in very different proteome patterns in

468 these two species. The observed striking proteomic differences were achieved by these two

469 species in relatively short evolutionary time, which implies a high evolvability of the system.

470 However, the exact nature of proteomic differences is unknown (whether it is related to genes

471 duplication, amino acid substitution, gene expression pattern shift, alternative splicing or some

472 posttranslational modification), and at least part of the differences can be due to phenotypic 
473 plasticity. Thus, these species present an interesting system to further investigate mechanisms of

474 rapid proteome divergence.

\section{Distant proteomes in phylogenetically close species with similar habitat}

476

preferences. The third example, from the Littorina "saxatilis" group, suggests that different

477 proteomes can be generated by similar genomes even if corresponding species populate very

478 similar biotope. The three species in this group (L. arcana, L. compressa and L. saxatilis) have a

479 high degree of whole genome similarity, as was demonstrated by comparative genomic

480 hybridization [65]. Earlier molecular phylogenies were inconclusive regarding these species

481 relationships $[66,74,76]$ and different molecular markers clustered the three species of the

482 "saxatilis" group in all possible combinations [65,76,78-80,119], which is one line of evidence

483 for their close phylogenetic proximity and a recent evolutionary divergence (divergence time is

484 estimated as $\sim 1-1.5 \mathrm{Ma})[76]$.

485 In our proteomic tree, the first divergence event splits $L$. compressa from a tight alliance of 486 L. saxatilis / L. arcana (Fig. 1A). We found 11 species-specific markers for L. compressa and a 487 similar number of markers specific for the pair L. saxatilis / L. arcana, but only two markers 488 specific for $L$. arcana and none for $L$. saxatilis (Table 2). These results are congruent with the 489 fact that both $L$. saxatilis and $L$. arcana demonstrate parallel proteomic shifts along the vertical 490 shore gradient while $L$. compressa does not [70]. The separation of $L$. compressa at the 491 proteomic level partially resembles the foregoing case of L. fabalis and L. obtusata in a sense 492 that it occurs between very closely related species. However, unlike the latter pair, the proteome 493 divergence is not easily explained by ecology in this case. Both $L$. arcana and L. compressa are 494 very similar to $L$. saxatilis: their ranges and habitat distribution overlap [74,120]. Although $L$. 495 compressa was not recorded from fucoid-free substrates, unlike two other species, it invariably 
496 lives in sympatry with L. saxatilis. All three species are often found together on the same fucoids

497 and rocks within an intertidal area, and there are so far no data suggesting stronger differences in

498 ecological preferences between $L$. compressa $-L$. saxatilis than between $L$. saxatilis and $L$.

499 arcana. It is still possible that $L$. compressa occupies very specific microhabitats to be elucidated

500 in future studies. Alternatively, some hypothetical switch could have occurred in the molecular

501 machinery functioning of $L$. compress $a$. The last explanation suggests that speciation events

502 could be related not only to environmental shifts or niche expansion but also to changes in an

503 organism's patterns of interaction with the same (or very similar) environment. Among protein

504 markers specific to L. compressa we identified arginine kinase, fructose-bisphosphate aldolase

505 and glutathione-s-transferase. These enzymes are potentially related to stress adaptation (e.g.

506 isolation-related hypoxia during low tide; in details discussed in [70]); and such changes are

507 compatible with any of the two proposed explanations.

508 4. Strinkingly similar proteomes in phylogenetically close species. In contrast to the $L$.

509 compressa case discussed above, the pair L. saxatilis / L. arcana showed high proteome

510 similarity. In general, this similarity is expected pattern given the short divergence time and

511 overlapping habitats. What is surprising is that both "geographic location" and "body part"

512 showed stronger impacts on the proteome than "species"; i.e. the first split occurs between UK

513 and other regions (further discussed below), then between "foot + head" and "penis" samples,

514 and then between the species (Fig. 2). The misidentification of morphologically similar males of

515 L. saxatilis and L. arcana could not explain this pattern, because female "foot + head" samples

516 cluster together with male "foot + head" samples; and females of the two species are

517 unambiguously distinguishable. 
L. saxatilis and L. arcana have strikingly similar proteomes (at least in adults and the

519 analyzed body parts), even though they have different reproductive strategies (L. arcana is

520 oviparous while $L$. saxatilis is ovoviviparous) and demonstrate some differences in distribution,

521 morphology and genetics [65,76,78,82,119,121]. Given their genomic, morphological, ecological

522 and now even proteomic similarity, this pair of species raises intriguing evolutionary questions.

523 (1) What mechanisms maintain this similarity across their range? (2) What kind of barrier

524 separates them from each other given indirect evidence of gene flow between them [120-121]?

525 (3) What evolutionary forces drove their divergence in the first place?

526 Only two species-specific protein markers were detected in our analysis for L. arcana (and

527 none for L. saxatilis). Both L. arcana-specific markers (and one marker of L. compressa) proved

528 to belong to PPIase class of enzymes, the cyclophilins (Cyp) family. These ubiquitously

529 distributed enzymes are known to facilitate folding of certain proteins and thus regulate diverse

530 cellular processes [rev. in 122-124]. In mollusks, Cyps are expressed in hemocytes and gonads

531 and involved in immune response [125-126]. They also participate in the processes of

532 biomineralization during shell and radula formation [127-129]. These enzymes are believed to be

533 secreted to spatially organize matrix proteins, and thus to control crystallization. Hypothetically,

534 structural differences in Cyps between closely related species could cause tiny changes in this

535 process resulting in interspecies radula variation, which was documented for L. arcana and $L$.

536 compressa [74]. In our analyses we used head tissues including odontophore and radular

537 invagination, where radula synthesis occurs. Moreover, Cyp of L. saxatilis is expected to be

538 catalytically active as there are no substitutions in catalytically important amino acids (based on

539 Cyp-transcript sequence present in LSD transcriptome [66]). Further studies are needed to

540 examine the precise compartment of expression and functioning of the identified Cyps. 
542 different localities grouped by species implying a tight link between genome and proteome and a

543 minor influence of physical factors, locality or season. Nevertheless, the same clustering pattern

544 repetitively appeared within every Neritrema species: UK samples formed a distinct clade (Fig.

545 2), while continental samples clustered more often according to the tissue type. In the pair $L$.

546 arcana / L. saxatilis separation between UK and continental samples even precedes the

547 separation of the species (Fig. 2, S2 Table). L. saxatilis UK populations have been previously

548 shown genetically distinct from the mainland using mitochondrial markers $[64,130]$ and it has

549 been suggested that UK L. saxatilis persisted in the UK within some local refugium during the

550 last glacial maximum with following postglacial expansion to the British Islands, but not to the

551 mainland. European mainland populations of L. saxatilis were presumably recolonized from

552 other refugia than the UK [64,130]. The existence of a UK refugium has been also suggested for

553 L. compressa and L. arcana [130]. Our findings are well in line with such scenario. Moreover,

554 both "obtusata" species have possibly also survived in a hypothetical UK refugium, as a separate

555 UK-clade was also detected in these two species. Recently, a new phylogeographic study

556 suggested the UK as a possible glacial refugium for L. fabalis and L. obtusata [131]. Overall, we

557 observed a pattern of geographic isolation at the proteome level, which is very similar to effect

558 of the recent post-glacial history observed in mtDNA. It would be interesting to test this effect

559 further by proteomic analyses of other populations known to have survived in separate glacial

560 refugia, such as L. saxatilis, L. obtusata and L. fabalis in the Iberian peninsula, or L. saxatilis and

561 L. obtusata in North America.

562 6. Qualitative proteomics is not reliable for intergenera analysis. When qualitative data

563 of different genera are put into comparative analysis, proteomics cannot resolve their relationship 
564 (unlike the interspecies analysis). This occurs because too many proteins are already changed

565 and too few are conserved, yielding a low number of common "anchoring" proteins between

566 strongly diverged genera and poor grouping of the genera with comparably high binary

567 dissimilarity. This is well illustrated by short genera branches relative to species ones (Fig. 1,2).

568 Thus, although in our study genera clustered differently than in DNA-markers-based tree, this

569 result is not sufficient to claim a conflict between the two approaches in this case.

\section{Conclusions}

571 Here we evaluated the usefulness of the proteomic approach in comparative evolutionary

572 studies. Proteomics has an advantage of the ability to reflect the biochemical machinery of life in

573 comparison to morphological traits. In addition, it records the features undetected by genomic

574 approaches, such as stable patterns of molecular functioning (including those maintained by non-

575 genetic mechanisms, but crucial for typical species physiology). This allows to easily reveal

576 potentially adaptive differences (like fast evolving proteins) in diverging taxa. Owing to

577 incorporation of both slowly and fast evolving proteins, proteomes may be a basis for higher

578 resolution reconstruction than neutral DNA-markers at short evolutionary scales. For the same

579 reason proteome-based analysis is less informative for genera and higher rank taxa, because they

580 might have accumulated too many changed proteins. Our data demonstrate that, although there is

581 a clear connection between the proteome and genome, proteomic and neutral DNA-markers-

582 based evolutionary reconstructions can either agree or contradict each other, depending on

583 whether adaptive processes have been involved in the recent history of the taxa in comparison.

584 Any of the particular outcomes can be informative for the interpretation of species relationships,

585 their evolutionary histories, and the causal and functional background of their evolution.

\section{Acknowledgments}


587 This research was funded by Russian Foundation for Basic Research grants number 18-54-20001 and 18-34-00873

588

589

590

591

592

593

594

595

596

597

598

599

600

601

602

603

604

605

606

607

608

609

610

611

612

613

614

615

616

617

618

619

620 and by St. Petersburg State University grant number 0.40.491.2017. The opportunities for 2D DIGE and LC-MS were provided by the Resource Center "Molecular and Cell Technologies" of St Petersburg State University; the opportunities for laboratory maintenance of experimental animals were provided by the Resource Center "Observatory of environmental safety" of St Petersburg State University; the oopurtunities of snails collection at the White Sea coast were provided by Educational and research station "Belomorskaia" of St Petersburg State University. We thank David G. Reid for his kind help with species identifications of the Littoraria and Echinolittorina snails, Anna Gonchar for proofreading and language editing; two anonymous Reviewers for valuable and very helpful comments on the manuscript.

\section{References}

1. Schluter D. Evidence for ecological speciation and its alternative. Science. 2009; 323(5915): 737-741. doi: 10.1126/science. 1160006

2. Nosil P. Ecological speciation. Oxford University Press: Oxford, UK. 2012. 304 p.

3. Elmer KR, Meyer A. Adaptation in the age of ecological genomics: insights from parallelism and convergence. Trends Ecol Evolut. 2011; 26(6): 298-306. doi: 10.1016/j.tree.2011.02.008

4. Martin A, Orgogozo V. The loci of repeated evolution: a catalog of genetic hotspots of phenotypic variation. Evolution. 2013; 67(5): 1235-1250. doi: 10.1111/evo.12081

5. Zuckerkandl E, Pauling L (1962) Molecular disease, evolution and genic heterogeneity. In: Kasha M, Pullman B, eds. Horizons in biochemistry. New York: Academic Press. pp. 189-225.

6. Kimura, M. (1968). Evolutionary rate at the molecular level. Nature, 217(5129), 624-626.

7. Felsenstein, J. (1988). Phylogenies from molecular sequences: inference and reliability. Annual review of genetics, 22(1), 521-565.

8. Maddison, W. P. (1997). Gene trees in species trees. Systematic biology, 46(3), 523-536.

9. Edwards SV. Is a new and general theory of molecular systematics emerging? Evolution. 2009; 63(1): 1-19. doi: 10.1111/j.1558-5646.2008.00549.x

10. Schlötterer C. The evolution of molecular markers - just a matter of fashion? Nature Rev Genet. 2004; 5(1): 63. doi: $10.1038 / \mathrm{nrg} 1249$

11. Patwardhan A, Ray S, Roy A, Molecular Markers in Phylogenetic Studies - A Review. J Phylogenetics Evol Biol. 2014; 2(131): 2. doi: 10.4172/2329-9002.1000131

12. Grover A, Sharma PC. Development and use of molecular markers: past and present. Crit Rev Biotechnol. 2016; 36(2): 290-302. doi: 10.3109/07388551.2014.959891

13. Degnan JH, Rosenberg NA. Gene tree discordance, phylogenetic inference and the multispecies coalescent. Trends in Ecology \& Evolution. 2009; 24(6): 332-340. doi: 10.1016/j.tree.2009.01.009 
621

622

623

624

625

626

627

628

629

630

631

632

633

634

635

636

637

638

639

640

641

642

643

644

645

646

647

648

649

650

651

652

653

654

14. Brito PH \& Edwards SV. Multilocus phylogeography and phylogenetics using sequence-based markers. Genetica. 2009; 135(3): 439-445. doi: 10.1007/s10709-008-9293-3

15. Lemmon EM, Lemmon AR. High-throughput genomic data in systematics and phylogenetics. Annu Rev Ecol Evol Syst. 2013; 44: 99-121. doi: 10.1146/annurev-ecolsys-110512-135822

16. Kuhner MK, Yamato J, Felsenstein J. Maximum likelihood estimation of population growth rates based on the coalescent. Genetics. 1998; 149(1): 429-434

17. Beerli P, Felsenstein J. Maximum-likelihood estimation of migration rates and effective population numbers in two populations using a coalescent approach. Genetics. 1999; 152(2): 763-773

18. Luikart G, England PR, Tallmon D, Jordan S, Taberlet P. The power and promise of population genomics: from genotyping to genome typing. Nature Rev Genet. 2003; 4(12): 981. doi: 10.1038/nrg1226

19. Noor MA, Feder JL. Speciation genetics: evolving approaches. Nature Rev Genet. 2006; 7(11): 851. doi:

\section{$10.1038 / \operatorname{nrg} 1968$}

20. Michel AP, Sim S, Powell TH, Taylor MS, Nosil P, Feder JL. Widespread genomic divergence during sympatric speciation. PNAS. 2010; 201000939. doi 10.1073/pnas.1000939107

21. Feder JL, Egan SP, Nosil P. The genomics of speciation-with-gene-flow. Trends Genet. 2012; 28(7): 342350. doi: 10.1016/j.tig.2012.03.009

22. Ravinet M, Faria R, Butlin RK, Galindo J, Bierne N, Rafajlović M, Noor MAF, Mehlig B, Westram AM. Interpreting the genomic landscape of speciation: a road map for finding barriers to gene flow. J Evol Biol. 2017; 30(8): 1450-1477. doi: 10.5061/dryad.qj5cr.

23 Cavalli-Sforza LL. Population structure and human evolution. Proc. R. Soc. Lond. B. 1964; 164: 362-379.

24 Rosenberg NA. Discordance of species trees with their most likely gene trees: a unifying principle. Mol Biol

Evol. 2013; 30(12): 2709-2713. doi: 10.1093/molbev/mst160

25 Degnan JH, Rosenberg NA. Discordance of species trees with their most likely gene trees. 2006; PLoS Genet. 2: 762-768. doi: 10.1371/journal.pgen.0020068

26 Jewett EM, Rosenberg N A. iGLASS: an improvement to the GLASS method for estimating species trees from gene trees. J Comput Biol. 2012; 19(3), 293-315. doi: 10.1089/cmb.2011.0231

27 Edwards SV. Is a new and general theory of molecular systematics emerging? Evolution: International Journal of Organic Evolution. 2009; 63(1): 1-19. doi: 10.1111/j.1558-5646.2008.00549.x

28. Edwards D \& Batley J. Plant bioinformatics: from genome to phenome. TRENDS in Biotechnology, 2004; 22(5), 232-237. doi:10.1016/j.tibtech.2004.03.002

29. Patti GJ, Yanes O, Siuzdak G. Innovation: Metabolomics: the apogee of the omics trilogy. Nature Reviews Molecular Cell Biology. 2012; 13(4), 263-269. doi:10.1038/nrm3314

30. Mameli M. Non-genetic selection and nongenetic inheritance. Br J Philos Sci. 2004; 55(1): 35-71. doi:

\section{$10.1093 /$ bjps $/ 55.1 .35$}

Peer] reviewing PDF | (2019:08:40334:2:0:NEW 5 Jan 2020) 
655

656

657

658

659

660

661

662

663

664

665

666

667

668

669

670

671

672

673

674

675

676

677

678

679

680

681

682

683

684

685

686

687

688

31. Bonduriansky R, Day T. Nongenetic inheritance and its evolutionary implications. Annu Rev Ecol Evol Syst. 2009; 40: 103-125. doi: 10.1146/annurev.ecolsys.39.110707.173441

32. Danchin É, Charmantier A, Champagne FA, Mesoudi A, Pujol B, Blanchet S. Beyond DNA: integrating inclusive inheritance into an extended theory of evolution. Nature Rev Genet. 2011; 12(7): 475. doi: $10.1038 / \operatorname{nrg} 3028$

33. Pigliucci M. An extended synthesis for evolutionary biology. Ann NY Acad Sci. 2009; 1168(1): 218-228. doi: 10.1111/j.1749-6632.2009.04578.x

34. Pigliucci M, Müller G. Evolution-the extended synthesis. MIT Press: Cambridge, US, 2010. 495 p.

35. Laland KN, Uller T, Feldman MW, Sterelny K, Müller GB, Moczek A, Jablonka E, Odling-Smee J. The extended evolutionary synthesis: its structure, assumptions and predictions. Proc R Soc B. 2015; 282(1813): 20151019. doi: $10.1098 / \mathrm{rspb} .2015 .1019$

36. Laland K, Uller T, Feldman M, Sterelny K, Müller GB, Moczek A, Jablonka E, Odling-Smee J, Wray GA, Hoekstra HE, Futuyma DJ, Lenski RE, Mackay TFC, Schluter D, Strassmann JE. Does evolutionary theory need a rethink? Nature. 2014; 514(7521): 161.

37. Salzburger W. Understanding explosive diversification through cichlid fish genomics. Nat Rev Genet. 2018; 19(11), 705-717.

38. Fang B, Merilä J, Ribeiro F, Alexandre CM, Momigliano, P. Worldwide phylogeny of three-spined sticklebacks. Mol Phylogen Evol. 2018; 127, 613-625.

39. Via S. Natural selection in action during speciation. PNAS. 2009; 106(Supplement 1): 9939-9946. doi: doi.org/10.1073/pnas.0901397106

40. Karr TL. Application of proteomics to ecology and population biology. Heredity. 2008; 100(2): 200. doi: 10.1038/sj.hdy.6801008

41. Gygi SP, Rochon Y, Franza BR, Aebersold R. Correlation between protein and mRNA abundance in yeast. Mol Cell Biol 1999, 19(3): 1720-1730. doi: 10.1128/MCB.19.3.1720

42. Greenbaum D, Colangelo C, Williams K, Gerstein M. Comparing protein abundance and mRNA expression levels on a genomic scale. Genome Biol. 2003; 4(9): 117. doi: 10.1186/gb-2003-4-9-117

43. Mack PD, Kapelnikov A, Heifetz Y, Bender M. Mating-responsive genes in reproductive tissues of female Drosophila melanogaster. PNAS. 2006; 103(27): 10358-10363. doi: 10.1073/pnas.060404610

44. Waters KM, Pounds JG, Thrall BD. Data merging for integrated microarray and proteomic analysis. Brief Funct Genomics. 2006; 5(4): 261-272. doi: 10.1093/bfgp/ell019

45. Maier T, Güell M, Serrano L. Correlation of mRNA and protein in complex biological samples. FEBS Lett. 2009; 583(24): 3966-3973. doi: 10.1016/j.febslet.2009.10.036

46. Aquadro CF, Avise JC. Genetic divergence between rodent species assessed by using two-dimensional electrophoresis. PNAS. 1981; 78(6): 3784-3788. doi: 10.1073/pnas.78.6.3784

Peer) reviewing PDF | (2019:08:40334:2:0:NEW 5 Jan 2020) 
689

690

691

692

693

694

695

696

697

698

699

700

701

702

703

704

705

706

707

708

709

710

711

712

713

714

715

716

717

718

719

720

721

722

47. Ohnishi S, Kawanishi M, Watanabe TK. Biochemical phylogenies of Drosophila: protein differences detected by two-dimensional electrophoresis. Genetica. 1983; 61(1): 55-63.

48. Dworzanski JP, Snyder AP. Classification and identification of bacteria using mass spectrometry-based proteomics. Expert Rev Proteomic. 2005; 2(6): 863-878. doi: 10.1586/14789450.2.6.863

49. López JL. Role of proteomics in taxonomy: the Mytilus complex as a model of study. J Chromatogr B. 2005; 815(1-2): 261-274. doi: 10.1016/j.jchromb.2004.10.064

50. López JL. Applications of proteomics in marine ecology. MEPS, 2007; 332, 275-279. doi: $10.3354 / \operatorname{meps} 332275$

51. Biron DG, Loxdale HD, Ponton F, Moura H, Marché L, Brugidou C, Thomas F. Population proteomics: an emerging discipline to study metapopulation ecology. Proteomics. 2006; 6(6): 1712-1715. doi:

10.1002/pmic.200500423

52. Kim GH, Shim JB, Klochkova TA, West JA, Zuccarello GC. The utility of proteomics in algal taxonomy: Bostrychia radicans/B. moritziana (Rhodomelaceae, Rhodophyta) as a model study. J Phycol. 2008, 44(6): 15191528. doi: 10.1111/j.1529-8817.2008.00592.x

53. Diz AP, Martínez-Fernández M, Rolán-Alvarez E. Proteomics in evolutionary ecology: linking the genotype with the phenotype. Mol Ecol. 2012; 21(5): 1060-1080. doi: 10.1111/j.1365-294X.2011.05426.x

54. Baer B, Millar AH. Proteomics in evolutionary ecology. J Proteom. 2016; 135, 4-11. doi:

10.1016/j.jprot.2015.09.031

55. Sokolova IM, Berger VJ. Physiological variation related to shell colour polymorphism in White Sea Littorina saxatilis. J Exp Mar Biol Ecol. 2000; 245(1): 1-23. doi: 10.1016/S0022-0981(99)00132-X

56. Sokolova IM, Pörtner HO. Physiological adaptations to high intertidal life involve improved water conservation abilities and metabolic rate depression in Littorina saxatilis. MEPS. 2001a; 224: 171-186. doi:

$10.3354 /$ meps 224171

57. Sokolova I, Pörtner HO. Temperature effects on key metabolic enzymes in Littorina saxatilis and L. obtusata from different latitudes and shore levels. Mar Biol. 2001b; 139(1): 113-126. doi: 10.1007/s002270100557

58. Conde-Padín P, Caballero A, Rolán-Alvarez E. Relative role of genetic determination and plastic response during ontogeny for shell-shape traits subjected to diversifying selection. Evolution Int J Org Evolution. 2009; 63(5): 1356-1363. doi: 10.1111/j.1558-5646.2009.00636.x

59. Granovitch AI, Yagunova EB, Maximovich AN, Sokolova IM. Elevated female fecundity as a possible compensatory mechanism in response to trematode infestation in populations of Littorina saxatilis (Olivi). Int $\mathrm{J}$ Parasitol. 2009; 39(9): 1011-1019. doi: 10.1016/j.ijpara.2009.02.014

60. Johannesson K, Panova M, Kemppainen P, André C, Rolan-Alvarez E, Butlin RK. Repeated evolution of reproductive isolation in a marine snail: unveiling mechanisms of speciation. Philos Trans Royal Soc B. 2010; 365(1547): 1735-1747. doi: 10.1098/rstb.2009.0256

Peer) reviewing PDF | (2019:08:40334:2:0:NEW 5 Jan 2020) 
723

724

725

726

727

728

729

730

731

732

733

734

735

736

737

738

739

740

741

742

743

744

745

746

747

748

749

750

751

752

753

754

755

756

61. Martínez-Fernández M, de la Cadena MP, Rolán-Alvarez E. The role of phenotypic plasticity on the proteome differences between two sympatric marine snail ecotypes adapted to distinct micro-habitats. BMC Evol Biol. 2010; 10(1): 65. doi: 10.1186/1471-2148-10-65

62. Panova M, Boström J, Hofving T, Areskoug T, Eriksson A, Mehlig B, Mäkinen T, André C, Johannesson K. Extreme female promiscuity in a non-social invertebrate species. PLoS One. 2010; 5(3): e9640. doi:

10.1371/journal.pone.0009640

63. Ng TP, Davies MS, Stafford R, Williams GA. Mucus trail following as a mate-searching strategy in mangrove littorinid snails. Animal Behav. 2011; 82(3): 459-465. doi: 10.1016/j.anbehav.2011.05.017

64. Panova M, Blakeslee AMH, Miller AW, Mäkinen T, Ruiz GM, Johannesson K, André C. Glacial history of the North Atlantic marine snail, Littorina saxatilis, inferred from distribution of mitochondrial DNA lineages. PLoS One. 2011; 6(3): e17511. doi: 10.1371/journal.pone.0017511

65. Panova M, Johansson T, Canbäck B, Bentzer J, Rosenblad MA, Johannesson K, Tunlid A, André C. Species and gene divergence in Littorina snails detected by array comparative genomic hybridization. BMC Genomics. 2014; 15(1): 687. doi: 10.1186/1471-2164-15-687

66. Canbäck B, André C, Galindo J, Johannesson K, Johansson T, Panova M, Tunlid A, Butlin R. The Littorina sequence database (LSD)-an online resource for genomic data. Mol Ecol Resour. 2012; 12(1): 142-148. doi: 10.1111/j.1755-0998.2011.03042.x

67. Storey KB, Lant B, Anozie OO, Storey JM. Metabolic mechanisms for anoxia tolerance and freezing survival in the intertidal gastropod, Littorina littorea. Comp Biochem Physiol A Mol Integr Physiol. 2013; 165(4): 448-459. doi: 10.1016/j.cbpa.2013.03.009

68. Rolán-Alvarez E, Austin C, Boulding EG. The contribution of the genus Littorina to the field of evolutionary ecology. Oceanogr Mar Biol: an Annual Review. 2015; 53: 157-214.

69. García-Souto D, Alonso-Rubido S, Costa D, Eirín-López J, Rolán-Álvarez E, Faria R, Galindo J, Pasantes JJ. Karyotype characterization of nine periwinkle species (Gastropoda, Littorinidae). Genes. 2018; 9(11): 517. doi: $10.3390 /$ genes 9110517

70. Maltseva AL, Varfolomeeva MA, Lobov AA, Mikhailova NA, Renaud PE, Grishankov AV, Volovik KY, Granovitch AI. Measuring physiological similarity of closely related littorinid species: a proteomic insight. MEPS. 2016; 552: 177-193. doi: 10.3354/meps11770

71. Muraeva OA, Maltseva AL, Mikhailova NA, Granovitch AI. Mechanisms of adaption to salinity stress in marine gastropods Littorina saxatilis: a proteomic analysis. Cell Tissue Biol. 2016; 10(2): 160-169. doi: 10.1134/S1990519X16020085

72. Lobov AA, Maltseva AL, Starunov VV, Babkina IY, Ivanov VA, Mikhailova NA, Granovitch AI. LOSP: A putative marker of parasperm lineage in male reproductive system of the prosobranch mollusk Littorina obtusata. J Exp Zool B Mol Dev Evol. 2018; 330(4): 193-201. doi: 10.1002/jez.b.22803 
757

758

759

760

761

762

763

764

765

766

767

768

769

770

771

772

773

774

775

776

777

778

779

780

781

782

783

784

785

786

787

788

789

790

73. Lobov AA, Maltseva AL, Mikhailova NA, Granovitch AI. LOSP: a newly identified sperm protein from Littorina obtusata. J Molluscan Stud. 2015; 81(4): 512-515.

74. Reid DG. Systematics and Evolution of Littorina. Ray Society: London, UK, 1996.

75. Reid DG. The comparative morphology, phylogeny and evolution of the gastropod family Littorinidae. Phil Trans R Soc Lond B. 1989; 324(1220): 1-110. doi: 10.1098/rstb.1989.0040

76. Reid DG, Dyal P, Williams ST. A global molecular phylogeny of 147 periwinkle species (Gastropoda, Littorininae). Zool Scr. 2012; 41(2): 125-136. doi: 10.1111/j.1463-6409.2011.00505.x

77. Crossland S, Coates D, Grahame J, Mill PJ. The Littorina saxatilis species complex - interpretation using random amplified polymorphic DNAs. Origin and evolutionary radiation of the Mollusca. Oxford University press; Oxford, UK, 1996. pp 205-209.

78. Wilding CS, Grahame J, Mill PJ. Mitochondrial DNA CoI haplotype variation in sibling species of rough periwinkles. Heredity. 2000a; 85(1): 62-74. doi: 10.1046/j.1365-2540.2000.00718.x

79. Wilding CS, Grahame J, Mill PJ. Nuclear DNA restriction site polymorphisms and the phylogeny and population C structure of an intertidal snail species complex (Littorina). Hereditas. 2000b; 133(1): 9-18. doi: 10.1111/j.1601-5223.2000.00009.x

80. Small MP, Gosling EM. Genetic structure and relationships in the snail species complex Littorina arcana Hannaford Ellis, L. compressa Jeffreys and L. saxatilis (Olivi) in the British Isles using SSCPs of cytochrome-b fragments. Heredity. 2000; 84(6): 692-701. doi: 10.1046/j.1365-2540.2000.00717.x

81. Reid DG, Dyal P, Williams S T. Global diversification of mangrove fauna: a molecular phylogeny of Littoraria (Gastropoda: Littorinidae). Mol Phylogenetics Evol. 2010; 55: 185-201. doi:

10.1016/j.ympev.2009.09.036

82. Granovitch AI, Loskutova ZI, Gracheva YA, Mikhailova NA. Morphometric comparison of the copulatory organ in mollusks of "saxatilis" species complex (Caenogastropoda: Littorinidae): problems of identification of species and species status. Zool Zh. 2008; 87(12): 1425-1436. doi: 10.1007/s10709-013-9728-3

83. Reid DG. Mainwaringia Nevill, 1885, a littorinid genus from Asiatic mangrove forests, and a case of protandrous hermaphroditism. J Molluscan Stud. 1986; 52(3): 225-242. doi: 10.1093/mollus/52.3.225

84. Reid DG. The genus Echinolittorina Habe, 1956 (Gastropoda: Littorinidae) in the Indo-West Pacific Ocean. Zootaxa 1420. Magnolia Press: Auckland, New Zealand, 2007. 161 pp.

85. Karp NA, Spencer M, Lindsay H, O'Dell K, Lilley KS. Impact of replicate types on proteomic expression analysis. J Proteome Res. 2005; 4(5): 1867-1871. doi: 10.1021/pr050084g

86. Messana I, Cabras T, Iavarone F, Vincenzoni F, Urbani A, Castagnola M. Unraveling the different proteomic platforms. J Sep Sci, 2013; 36(1): 128-139. doi: 10.1002/jssc.201200830

87. Arentz G, Weiland F, Oehler MK, Hoffmann P. State of the art of 2D DIGE. Proteomics Clin Appl. 2015; 9(3-4): 277-288. doi: 10.1002/prca.201400119

Peer) reviewing PDF | (2019:08:40334:2:0:NEW 5 Jan 2020) 
791

792

793

794

795

796

797

798

799

800

801

802

803

804

805

806

807

808

809

810

811

812

813

814

815

816

817

818

819

820

821

822

823

824

88. Ünlü M, Morgan ME, Minden JS. Difference gel electrophoresis. A single gel method for detecting changes in protein extracts. Electrophoresis. 1997; 18(11): 2071-2077.doi: 10.1002/elps.1150181133

89. Lilley KS, Friedman DB. All about DIGE: quantification technology for differential-display 2D-gel proteomics. Expert Rev Proteomics. 2004; 1(4): 401-409. doi: 10.1586/14789450.1.4.401

90. Berth M, Moser FM, Kolbe M, Bernhardt J. The state of the art in the analysis of two-dimensional gel electrophoresis images. Appl Microbiol Biotechnol. 2007; 76(6): 1223-1243. doi: https://doi.org/10.1007/s00253007-1128-0

91. R Core Team (2015). R: A language and environment for statistical computing. R Foundation for Statistical Computing, Vienna, Austria. URL https://www.R-project.org/.

92. Galili T. dendextend: an R package for visualizing, adjusting and comparing trees of hierarchical clustering. Bioinformatics. 2015; 31(22): 3718-3720. doi: 10.1093/bioinformatics/btv428

93. Shimodaira H. Approximately unbiased tests of regions using multistep-multiscale bootstrap resampling.

Ann Stat. 2004; 32(6): 2616-2641. doi: 10.1214/009053604000000823

94. Suzuki R, Shimodaira H. Pvclust: an R package for assessing the uncertainty in hierarchical clustering.

Bioinformatics. 2006; 22 (12): 1540-1542. doi: 10.1093/bioinformatics/btl117

95. Efron B, Halloran E, Holmes S. Bootstrap confidence levels for phylogenetic trees. Proceedings of the National Academy of Sciences USA. 1996; 93: 13429-13434.

96. Paradis E, Schliep K. ape 5.0: an environment for modern phylogenetics and evolutionary analyses in R. Bioinformatics. 2018; 35: 526-528.

97. Hennig C. Cluster-wise assessment of cluster stability. Comput Stat Data Anal. 2007; 52(1): 258-271. doi:

10.1016/j.csda.2006.11.025

98. Hennig C. Dissolution point and isolation robustness: robustness criteria for general cluster analysis methods.

J Multivar Anal. 2008; 99(6): 1154-1176. doi: 10.1016/j.jmva.2007.07.002

99. Hennig C. (2015). fpc: Flexible Procedures for Clustering (Version 2.1-10).

100. De Cáceres M, Legendre P. Associations between species and groups of sites: indices and statistical inference. Ecology. 2009; 90(12): 3566-3574. doi: 10.1890/08-1823.1

101. Feng S, Bootsma M, McLellan SL. Human-associated Lachnospiraceae genetic markers improve detection of fecal pollution sources in urban waters. Appl Environ Microbiol. 2018; 84(14): pp.e00309-18. doi:

10.1128/AEM.00309-18

102. Benjamini Y, Hochberg Y. Controlling the false discovery rate: a practical and powerful approach to multiple testing. J Royal Stat Soc. 1995; 289-300.

103. Ronquist F, Huelsenbeck JP. MrBayes 3: Bayesian phylogenetic inference under mixed models.

Bioinformatics. 2003; 19(12): 1572-1574. doi: 10.1093/bioinformatics/btg180

104. Schliep KP. phangorn: Phylogenetic analysis in R. Bioinformatics. 2011; 27(4): 592-593.

Peer) reviewing PDF | (2019:08:40334:2:0:NEW 5 Jan 2020) 
825

826

827

828

829

830

831

832

833

834

835

836

837

838

839

840

841

842

843

844

845

846

847

848

849

850

851

852

853

854

855

856

857

105. Robinson DF, Foulds LR (1981) Comparison of phylogenetic trees, Mathematical Biosciences, 53(1), 131147

106. Fowlkes EB, Mallows CL. A method for comparing two hierarchical clusterings. J Am Stat Assoc. 1983; 78(383): 553-569.

107. Sokal RR, Rohlf FJ. The comparison of dendrograms by objective methods. Taxon. 1962; 33-40. doi: $10.2307 / 1217208$

108. Uda K, Fujimoto N, Akiyama Y, Mizuta K, Tanaka K, Ellington WR, Suzuki T. Evolution of the arginine kinase gene family. Comp Biochem Physiol Part D: Genomics and Proteomics. 2006; 1(2), 209-218.

109. Storz JF. Causes of molecular convergence and parallelism in protein evolution. Nature Rev Genet. 2016; 17(4): 239. doi: $10.1038 / \mathrm{nrg} .2016 .11$

110. Zou Z, Zhang J. Are convergent and parallel amino acid substitutions in protein evolution more prevalent than neutral expectations? Mol Biol Evol. 2015; 32(8): 2085-2096. doi: 10.1093/molbev/msv091

111. Starr TN, Thornton JW. Epistasis in protein evolution. Protein Sci. 2016; 25(7): 1204-1218. doi: $10.1002 /$ pro. 2897

112. Lee OH, Williams GA, Hyde KD. The diets of Littoraria ardouiniana and L. melanostoma in Hong Kong mangroves. JMBA. 2001; 81(6): 967-973. doi: 10.1017/S002531540100491X

113. Lee OH, Williams GA. Spatial distribution patterns of Littoraria species in Hong Kong mangroves.

Hydrobiologia. 2002a; 481(1-3): 137-145. doi: 10.1023/A:1021241810526

114. McMahon RF. Respiratory response to periodic emergence in intertidal molluscs. Amer Zool. 1988; 28(1): 97-114. doi: 10.1093/icb/28.1.97

115. Lee OH, Williams GA. Locomotor activity patterns of the mangrove littorinids, Littoraria ardouiniana and L. melanostoma, in Hong Kong. J Molluscan Stud. 2002b; 68(3): 235-241. doi: 10.1093/mollus/68.3.235

116. Granovitch AI, Mikhailova NA, Znamenskaya O, Petrova YA. Species complex of mollusks of the genus Littorina (Gastropoda: Prosobranchia) from the eastern Murman coast. Zool Zh. 2004; 83(11): 1305-1316. doi: 10.1007/s10709-009-9397-4

117. Kemppainen P, Panova M, Hollander J, Johannesson K. Complete lack of mitochondrial divergence between two species of NE Atlantic marine intertidal gastropods. J Evol Biol. 2009; 22(10): 2000-2011. doi: 10.1111/j.1420-9101.2009.01810.x

118. Carvalho, J., Pereira, C., Sotelo, G., Costa, D., Galindo, J., \& Faria, R. De novo isolation of 17 microsatellite loci for flat periwinkles (Littorina fabalis and L. obtusata) and their application for species discrimination and hybridization studies. J Moll Stud. 2015; 81(3): 421-425. doi: 10.1093/mollus/eyv014 119. Knight AJ, Ward RD. The genetic relationships of three taxa in the Littorina saxatilis species complex (Prosobranchia: Littorinidae). J Molluscan Stud. 1991; 57(1): 81-91. doi: 10.1093/mollus/57.1.81 
858

859

860

861

862

863

864

865

866

867

868

869

870

871

872

873

874

875

876

877

878

879

880

881

882

883

884

885

886

887

888

889

\section{Supporting information}

891 S1 Table. Raw data. Table of protein spots presence / absence in the samples of 10 Littorinid species.

120. Granovitch AI, Maximovich AN, Avanesyan AV, Starunova ZI, Mikhailova NA. Micro-spatial distribution of two sibling periwinkle species across the intertidal indicates hybrdization. Genetica. 2013; 141(7-9): 293-301. doi: 10.1007/s10709-013-9728-3

121. Mikhailova NA, Gracheva YA, Backeljau T, Granovitch AI. A potential species-specific molecular marker suggests interspecific hybridization between sibling species Littorina arcana and L. saxatilis (Mollusca, Caenogastropoda) in natural populations. Genetica. 2009; 137(3): 333. doi: 10.1007/s10709-009-9397-4

122. Galat A, Metcalfe SM. Peptidyl proline cis/trans isomerases. Prog Biophys Mol Biol. 1995; 63(1): 67-118. doi: 10.1016/0079-6107(94)00009-X

123. Fischer G, Aumüller T. Regulation of peptide bond cis/trans isomerization by enzyme catalysis and its implication in physiological processes. Rev Physiol Bioch P. 2003; 105-150. Springer, Berlin, Heidelberg. doi: 10.1007/s10254-003-0011-3

124. Lu KP, Finn G, Lee TH, Nicholson LK. Prolyl cis-trans isomerization as a molecular timer. Nat Chem Biol. 2007; 3(10): 619. doi: 10.1038/nchembio.2007.35

125. Song X, Wang L, Song L, Zhao J, Zhang H, Zheng P, Qiu L, Liu X, Wu L. A cyclophilin A inducible expressed in gonad of zhikong scallop Chlamys farreri. Mol Biol Rep. 2009; 36(6): 1637. doi: 10.1007/s11033-0089363-8

126. Ji C, Wu H, Wei L, Zhao J, Wang Q, Lu H. Responses of Mytilus galloprovincialis to bacterial challenges by metabolomics and proteomics. Fish Shellfish Immun. 2013, 35(2): 489-498. doi: 10.1016/j.fsi.2013.05.009

127. Jackson DJ, McDougall C, Woodcroft B, Moase P, Rose RA, Kube M, Reinhardt R, Rokhsar DS, Montagnani C, Joubert C, Piquemal D, Degnan BM. Parallel evolution of nacre building gene sets in molluscs. Mol Biol Evol. 2009; 27(3): 591-608. doi: 10.1093/molbev/msp278

128. Marie B, Jackson DJ, Ramos-Silva P, Zanella-Cléon I, Guichard N, Marin F. The shell-forming proteome of Lottia gigantea reveals both deep conservations and lineage-specific novelties. FEBS J. 2013; 280(1): 214-232. doi: 10.1111/febs. 12062

129. Nemoto M, Wang Q, Li D, Pan S, Matsunaga T, Kisailus D. Proteomic analysis from the mineralized radular teeth of the giant Pacific chiton, Cryptochiton stelleri (Mollusca). Proteomics. 2012; 12(18): 2890-2894. doi: 10.1002/pmic. 201100473

130. Doellman MM, Trussell GC, Grahame JW, Vollmer SV. Phylogeographic analysis reveals a deep lineage split within North Atlantic Littorina saxatilis. Proc Royal Soc B. 2011; 278(1722): 3175-3183. doi:

10.1098/rspb.2011.0346

131. Sotelo G, Duvetorp M, Costa D, Panova M, Johannesson K \& Faria R. Phylogeographic history of flat periwinkles, Littorina fabalis and L. obtusata. BMC Evol Biol. 2019. In press

Peer) reviewing PDF | (2019:08:40334:2:0:NEW 5 Jan 2020) 
892 S2 Table. Cluster stability analysis results. The stability of sample clustering for a tree obtained using unweighted pair 893 group method with arithmetic mean (UPGMA) on the matrix of pairwise Jaccard dissimilarities based on presence/absence of 894 proteins in the samples. The original tree was split into a specified number of clusters; and the cluster-wise index of cluster

895 stability was computed as a mean Jaccard similarity of the actual cluster to the most similar cluster in a bootstrapped data. The 896 columns are as follows: $n \_c l$ - the number of clusters data were splitted into; cl_id - unique identification number of a cluster

897 after splitting; mean_j - mean Jaccard similarity index within a cluster; $s d \_j$ - standard deviation of mean_j; recover_prob - the

898 percentage of 10000 bootstrap iterations bringing clusters with mean $\_j>0.75$; dissolved_prob - the percentage of 10000

899 bootstrap iterations bringing clusters with mean_j $<0.5$; cl_cont - cluster composition.

900 S3 Table. Cluster specific protein markers. Upper part: generalized scheme of spots based on comparative 2D DIGE

901 analysis in PDQuest software. Protein markers are highlighted by species or combination of species the markers belong to (the

902 color legend is located in the lower part of the figure). The markers with maximal specificity (A) and sensitivity (B) are

903 numbered. Numbering is independent within every square; each square can be identified by latitude (capital letter) and longitude 904 (lowercase letter). The unique coordinates of the markers are represented in the table below ("mapping" column). Colored spots 905 without numbers are markers with A and B indexes lesser than 1; e.g. expressed in not supported clusters (like "saxatilis"-group +

906 L. fabalis): or not in all samples of the particular cluster (only in a certain body part or in a certain location): respectively. Lower

907 part: table of identified cluster markers. Only markers with specificity (A) and sensitivity (B) indexes exceeding 0.5 are shown;

908 data on markers with non-maximal A and B indexes are written in italic. For markers identified by LC-MS analysis the name and 909 database ID of the proteins are presented in the "protein details" column.

910 S1 File. Methods details.

911 S2 File. Proteomes clustering.

912 


\section{Figure 1}

Interspecies relations within the family Littorinidae

(A) Dendrogram of consensus species proteomes obtained via neighbour joining based on Jaccard dissimilarities of protein occurrence frequency in samples of different species. The bootstrap support values are shown. (B) The molecular phylogeny tree obtained via Bayesian inference using concatenated partial gene sequences from 28S rRNA, 12S rRNA and cytochrome oxidase C subunit I (COI). Support values are posterior probabilities. Prior to comparison, the both trees $A$ and $B$ were made ultrametric using non-negative least squares. Robinson-Foulds distance between unrooted trees was RF $=2$ (normalized RF $=0.143$ ). The cophenetic correlation between trees $A$ and $B$ is $C C=0,801$; between raw $\mathrm{NJ}$ and Bayesian trees is 0.798 (C) Fowlkes-Mallows index comparing dendrograms $A$ and B. Black line with dots shows the change of the compositional similarity of clusters (Bk) with the number of clusters (k). Dashed line indicates Bk values under a null hypothesis of insignificant similarity of cluster' composition in the trees under comparison). Red line depicts threshold values for rejection of the null hypothesis. (D) Matrices of cophenetic distances for the proteomic and DNA-based trees expressed as a percentage of the total tree length. L. lit Littorina (Littorina) littorea, L. obt Littorina (Neritrema) obtusata, L. fab Littorina (Neritrema) fabalis, L. sax Littorina (Neritrem) saxatilis, L. arc Littorina (Neritrema) arcana, L. com Littorina (Neritrema) compressa, L. ard Littoraria ardouiniana, L. mel Littoraria melanostoma, E. mil Echinolittorina millegrana, E. mar Echinolittorina marisrubri 

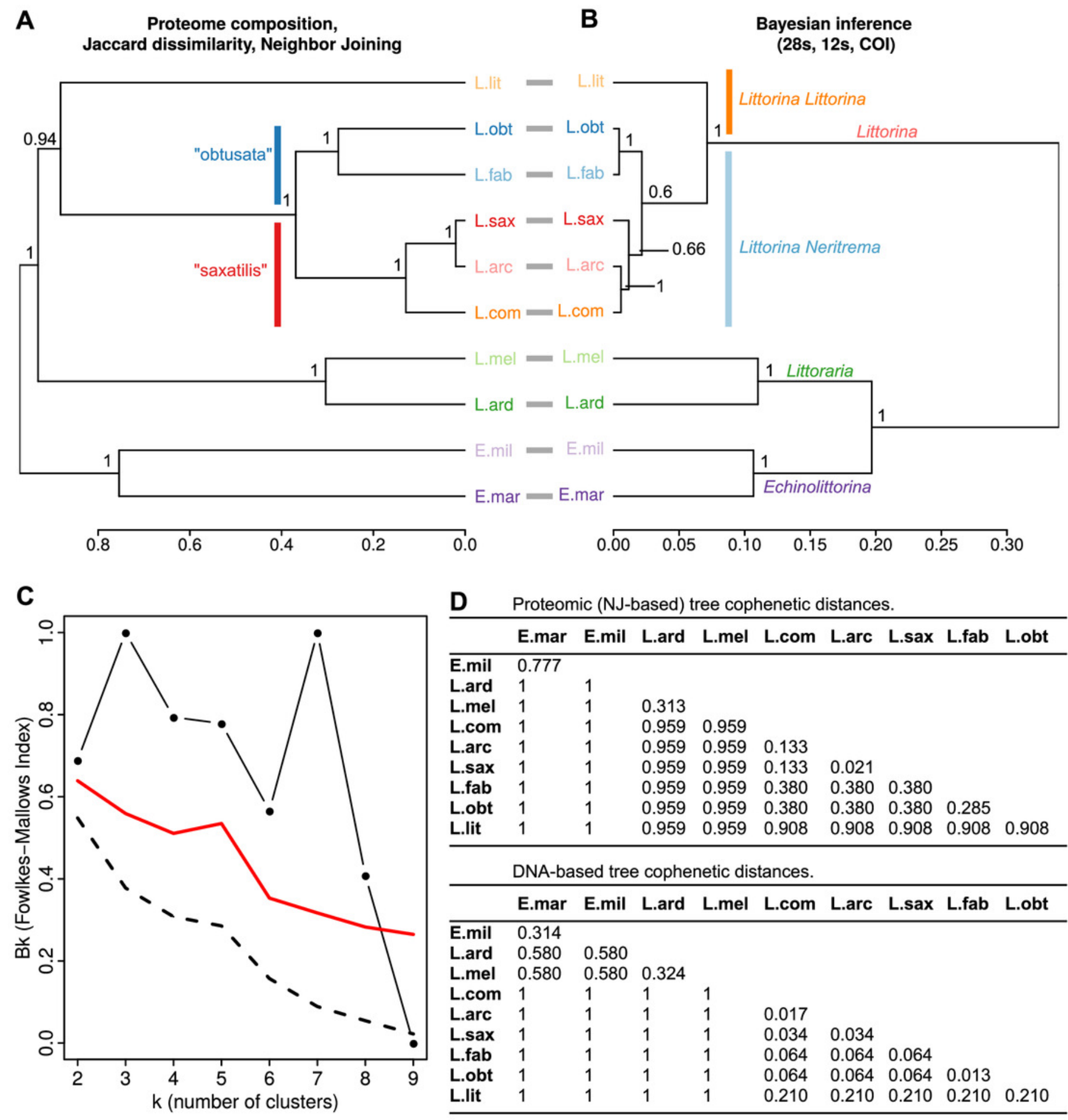

D Proteomic (NJ-based) tree cophenetic distances.

\begin{tabular}{llllllllll}
\hline & E.mar & E.mil & L.ard & L.mel & L.com & L.arc & L.sax & L.fab & L.obt \\
\hline E.mil & 0.777 & & & & & & & & \\
L.ard & 1 & 1 & & & & & & & \\
L.mel & 1 & 1 & 0.313 & & & & & & \\
L.com & 1 & 1 & 0.959 & 0.959 & & & & & \\
L.arc & 1 & 1 & 0.959 & 0.959 & 0.133 & & & & \\
L.sax & 1 & 1 & 0.959 & 0.959 & 0.133 & 0.021 & & & \\
L.fab & 1 & 1 & 0.959 & 0.959 & 0.380 & 0.380 & 0.380 & & \\
L.obt & 1 & 1 & 0.959 & 0.959 & 0.380 & 0.380 & 0.380 & 0.285 & \\
L.lit & 1 & 1 & 0.959 & 0.959 & 0.908 & 0.908 & 0.908 & 0.908 & 0.908 \\
\hline
\end{tabular}

DNA-based tree cophenetic distances.

\begin{tabular}{llllllllll}
\hline & E.mar & E.mil & L.ard & L.mel & L.com & L.arc & L.sax & L.fab & L.obt \\
\hline E.mil & 0.314 & & & & & & & & \\
L.ard & 0.580 & 0.580 & & & & & & & \\
L.mel & 0.580 & 0.580 & 0.324 & & & & & & \\
L.com & 1 & 1 & 1 & 1 & & & & & \\
L.arc & 1 & 1 & 1 & 1 & 0.017 & & & & \\
L.sax & 1 & 1 & 1 & 1 & 0.034 & 0.034 & & & \\
L.fab & 1 & 1 & 1 & 1 & 0.064 & 0.064 & 0.064 & & \\
L.obt & 1 & 1 & 1 & 1 & 0.064 & 0.064 & 0.064 & 0.013 & \\
L.lit & 1 & 1 & 1 & 1 & 0.210 & 0.210 & 0.210 & 0.210 & 0.210 \\
\hline
\end{tabular}




\section{Figure 2}

Dendrogram of proteome UPGMA clustering from samples of the 10 Littorinidae species

Clustering was produced using unweighted pair group method with arithmetic mean (UPGMA) algorithm based on Jaccard dissimilarity coefficients for the data on presence/absence of proteins in the samples. Sample labels indicate species (L.arc: Littorina (Neritrema) arcana; L.comp: Littorina (Neritrema) compressa; L.sax: Littorina (Neritrema) saxatilis; L.obt: Littorina (Neritrema) obtusata; L.fab: Littorina (Neritrema) fabalis; L.lit: Littorina (Littorina) littorea; L.ard: Littoraria ardouiniana; L.mel: L. melanostoma; E.mar: Echinolittorina marisrubri; E.mil: E. millegrana), location (Ru: White Sea, Russia; Fr: English Channel, France; UK: Atlantic coast, Scotland; No: Barents Sea, Norway; Cn: East-China Sea, Hong Kong; Il: Israel), sex (f: female; m: male) and body part (so: foot + head parts; pe: penis). The approximately unbiased bootstrap support values are shown. (neighbor joining-based clustering is presented in S2 File) 


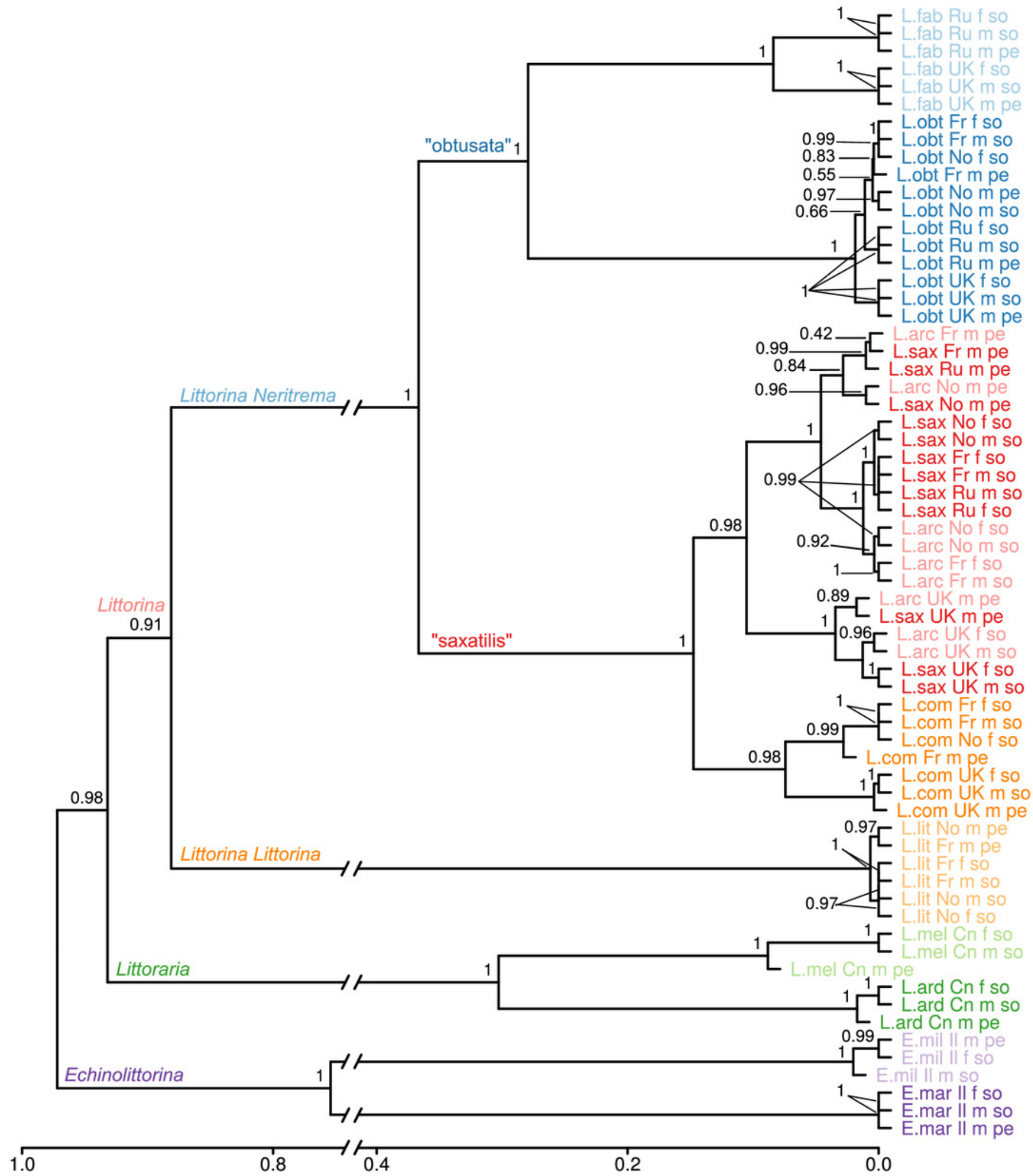




\section{Table $\mathbf{1}$ (on next page)}

Location of sampling sites, collection seasons, and sample composition 
1 Table 1. Location of sampling sites, collection seasons, and sample composition.

\begin{tabular}{|c|c|c|c|}
\hline Location & $\begin{array}{l}\text { Geographic } \\
\text { coordinates }\end{array}$ & Season & Collected species \\
\hline $\begin{array}{l}\text { Cancale, English } \\
\text { Channel, France }\end{array}$ & $\begin{array}{l}48^{\circ} 70^{\prime} \mathrm{N} \\
-1^{\circ} 84^{\prime} \mathrm{W}\end{array}$ & May, 2014 & $\begin{array}{l}\text { L. saxatilis, } \\
\text { L. arcana, } \\
\text { L. compressa, } \\
\text { L. obtusata, } \\
\text { L. littorea }\end{array}$ \\
\hline $\begin{array}{l}\text { Tromsø, Barents Sea, } \\
\text { Norway }\end{array}$ & $\begin{array}{l}69^{\circ} 43^{\prime} \mathrm{N} \\
18^{\circ} 60^{\prime} \mathrm{E}\end{array}$ & May, 2014 & $\begin{array}{l}\text { L. saxatilis, } \\
\text { L. arcana, } \\
\text { L. compressa, } \\
\text { L. obtusata, } \\
\text { L. littorea }\end{array}$ \\
\hline $\begin{array}{l}\text { Chupa Bay, White } \\
\text { Sea, Russia }\end{array}$ & $\begin{array}{l}66^{\circ} 29^{\prime} \mathrm{N} \\
33^{\circ} 68^{\prime} \mathrm{W}\end{array}$ & June, 2014 & $\begin{array}{l}\text { L. saxatilis } \\
\text { L. obtusata }\end{array}$ \\
\hline $\begin{array}{l}\text { Sheung Pak Nai, New } \\
\text { Territories, Hong } \\
\text { Kong, China }\end{array}$ & $\begin{array}{l}22^{\circ} 27^{\prime} \mathrm{N} \\
113^{\circ} 58^{\prime} \mathrm{E}\end{array}$ & August, 2014 & $\begin{array}{l}\text { L. ardouiniana } \\
\text { L. melanostoma }\end{array}$ \\
\hline Oban, Scotland, UK & $\begin{array}{l}56^{\circ} 27^{\prime} \mathrm{N} \\
5^{\circ} 27^{\prime} \mathrm{W}\end{array}$ & April, 2015 & $\begin{array}{l}\text { L. saxatilis, } \\
\text { L. arcana, } \\
\text { L. compressa, } \\
\text { L. obtusata } \\
\text { L. faballis }\end{array}$ \\
\hline Eilat, Red Sea, Israel & $\begin{array}{l}29^{\circ} 30^{\prime} \mathrm{N} \\
34^{\circ} 54^{\prime} \mathrm{E}\end{array}$ & August, 2015 & $\begin{array}{l}\text { E. millegrana } \\
\text { E. marisrubri }\end{array}$ \\
\hline
\end{tabular}




\section{Table 2 (on next page)}

Composition, protein markers and supporting values of sample clusters.

Selected clusters obtained from analysis of Jaccard dissimilarities for the full set of samples (the full list is presented in S1 Table). The first column indicates the composition of a cluster; the second is the number of protein markers, identifying the cluster with maximal specificity and sensitivity; the third is the threshold number of clusters when the cluster of this particular composition appears (from a minimal number of clusters to maximal); the fourth is the recovery probability of the particular composition cluster when it appears for the first time (e.g., the "saxatilis"-group cluster appeared at first during partition into 6 clusters; the recovery probability after this partition was 1 ; while this cluster persisted through 2 more partitions, its probability dropped to 0.99 and 0.90 , respectively). 
1 Table 2. Composition, protein markers and supporting values of sample clusters. Selected clusters obtained from 2 analysis of Jaccard dissimilarities for the full set of samples (the full list is presented in S1 Table). The first column 3 indicates the composition of a cluster; the second is the number of protein markers, identifying the cluster with 4 maximal specificity and sensitivity; the third is the threshold number of clusters when the cluster of this particular 5 composition appears (from a minimal number of clusters to maximal); the fourth is the recovery probability of the 6 particular composition cluster when it appears for the first time (e.g., the "saxatilis"-group cluster appeared at first 7 during partition into 6 clusters; the recovery probability after this partition was 1; while this cluster persisted through 82 more partitions, its probability dropped to 0.99 and 0.90 , respectively).

\begin{tabular}{|c|c|c|c|}
\hline Composition of clusters (CC) & $\begin{array}{l}\text { Number of } \\
\text { markers (NC) }\end{array}$ & $\begin{array}{l}\text { NC for the } \mathrm{CC} \\
\text { first appearance }\end{array}$ & $\begin{array}{l}\text { Recovery } \\
\text { probability }\end{array}$ \\
\hline Littoraria ardouiniana & 12 & 8 & 0.98 \\
\hline Littoraria melanostoma & 24 & 8 & 0.98 \\
\hline Echinolittorina marisrubri & 50 & 5 & 0.95 \\
\hline Echinolittorina millegrana & 58 & 5 & 0.94 \\
\hline Littorina Littorina littorea & 100 & 4 & 1 \\
\hline Littorina Neritrema fabalis & 28 & 7 & 0.92 \\
\hline Littorina Neritrema obtusata & 28 & 7 & 0.96 \\
\hline Littorina Neritrema arcana & 2 & - & - \\
\hline Littorina Neritrema compressa & 11 & 9 & 0.99 \\
\hline Littoraria (L. ardouiniana /+ L. melanostoma) & 74 & 7 & 0.82 \\
\hline Echinolittorina (E.millegrana + E.marisrubri) & 28 & 4 & 1 \\
\hline Littorina arcana + Littorina saxatilis & 15 & 9 & 0.89 \\
\hline $\begin{array}{l}\text { "saxatilis"-group (L. arcana }+ \text { L. saxatilis }+L . \\
\text { compressa) }\end{array}$ & 33 & 6 & 1 \\
\hline "obtusata" group (L. fabalis + L. obtusata) & 12 & 6 & 0.89 \\
\hline Littorina Neritrema & 153 & 2 & 1 \\
\hline
\end{tabular}


